\title{
Behaviour response of Namaqua Afrikaner, Dorper and South African Mutton Merino lambs towards humans
}

\author{
J.J.E. Cloete ${ }^{1,2 \#}$, S.W.P. Cloete ${ }^{2,3}$, A.J. Scholtz ${ }^{3}$ \& L.C. Hoffman ${ }^{2}$ \\ ${ }^{1}$ Elsenburg Agricultural Training Institute, Private Bag X1 Elsenburg 7607, South Africa \\ ${ }^{2}$ Department of Animal Science, University of Stellenbosch, Private Bag X1, Matieland 7599, South Africa \\ ${ }^{3}$ Institute for Animal Production: Elsenburg, Private Bag X1, Elsenburg 7607, South Africa
}

(Received 6 February 2013; Accepted 3 July 2013; First published online 18 September 2013)

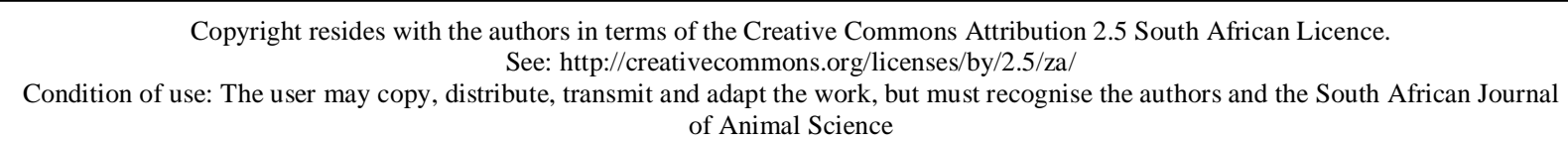

\begin{abstract}
The response of Namaqua Afrikaner, Dorper and South African Mutton Merino lambs, of approximately four months of age, towards a human being situated between them and their flock mates was studied in an arena test. The objective of the study was to determine whether the unimproved Namaqua Afrikaner, with an arguably shorter history of selection, would react differently to humans in an arena test compared to commercial breeds. A total number of 305 animals, born in 2010 and 2011 and raised under extensive veld conditions, were assessed in a modified arena test when the lambs born in each year were approximately four months old. From the test results it was possible to calculate the following parameters of the behaviour of the sheep: (i) The mean distance from the human operator, (ii) the time a lamb spent in a specific zone situated either close to or far from the human, and (iii) the total number of boundaries crossed, which gives an indication of the total distance travelled by an individual lamb. Other data recorded were the number of bleats and the number of times an animal urinated or defecated. There were no significant sex and birth type differences for any of the behaviour traits. No conclusive breed differences were found for any of the traits describing the behaviour of the lambs, except for the number of bleats. Namaqua Afrikaner lambs bleated significantly $(24.0 \pm 1.2)$ more in the three minute testing period than Dorper $(8.2 \pm 0.9)$ and South African Mutton Merino lambs (11.9 \pm 2.5$)$. Further research is necessary to see if this slight indication of anxiety could be related to other traits such as lamb survival or product quality.
\end{abstract}

Keywords: Arena test, distance travelled, times defecated, times urinated, sheep, stockman, temperament

${ }^{\#}$ Corresponding author E-mail: jasperc@elsenburg.com

\section{Introduction}

Temperament is defined as an animal's inherent response to a stressful stimulus and is determined by genetic and permanent environmental effects such as early life experience (Dodd et al., 2012). In measuring and selecting for temperament in livestock, producers want animals that are easier to handle in open situations, as well as in more restricted environments. Temperament is also believed to be linked to some production traits. In extensively reared and managed sheep it has been shown that temperament is related to the ability of ewes to rear their lambs (Murphy et al., 1994; Kilgour \& Szantar-Codington, 1995). Stress also influences meat quality (Cloete et al., 2005); syndromes such as pale, soft and exudative (PSE) meat in pork and dark, firm and dry (DFD) meat in beef may result from an inability of slaughter animals to cope with either acute short-term or chronic long-term stress (Lawrie, 1998). Cloete et al. (2005) found that Merino lambs more susceptible to stress had inferior meat quality. According to Murphy et al. (1994), animals of quiet temperament grew faster and were better producers than animals with restless, nervous or aggressive temperaments. Animal welfare considerations are increasingly becoming an important aspect of production 
and selection for temperament is seen as a potential way to reduce stress on farm animals without the need to alter management practices (Dodd et al., 2012).

The Dorper sheep is considered as the major meat breed in South Africa (24\% of records in the National Small stock Improvement Scheme; Cloete \& Olivier, 2010) and are normally farmed in extensive areas. The South African Mutton Merino (SAMM) is the major dual-purpose breed (6\% of records in the NSSIS; Cloete \& Olivier, 2010), and may be better suited for more intensive farming. In contrast, the Namaqua Afrikaner is only conserved in a few flocks. It is known from casual observations that Namaqua Afrikaners have strong flocking instincts. It has been suggested that separation from their flock mates could create stress in such animals (Hough, 2012). The objective of the study was therefore to determine whether unimproved indigenous Namaqua Afrikaner lambs would react differently to humans than commercial breeds.

\section{Materials and Methods}

The experiment was carried out on the Nortier experimental farm in the West Coast Strandveld area of

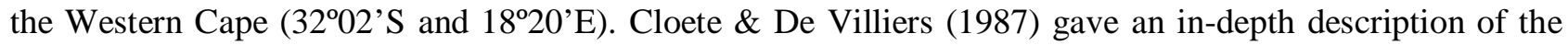
location and vegetation of the experimental farm: The climate is Mediterranean, with $76 \%$ of the total longterm annual precipitation of $221 \mathrm{~mm}$ being recorded during winter (April-September). The experimental site is characterised by dry, hot summers and cooler winters with an unpredictable and variable rainfall.

The responses of 305 Namaqua Afrikaner, Dorper and SAMM lambs (ram and ewe lambs), approximately four months old, were assessed in a modified arena test. The lambs were assessed in the arena shortly after weaning, and before being subjected to regular husbandry procedures involving routine handling. The arena test involved placing a single sheep in an arena $(8.0 \mathrm{~m} \mathrm{x} 6.0 \mathrm{~m})$. The floor of the arena was marked out in 12 numbered squares. At one end of, and outside, the arena was a pen containing six to seven weaners belonging to the same age group as the sheep being tested. An operator sat on a chair directly in front of this pen within the arena. The animals to be tested were kept in a separate pen out of sight. A second operator introduced the lamb to the arena at a distance of eight metres from the operator sitting on the chair. The lamb tested remained in the arena for three minutes and was observed by two recorders sitting at a location overlooking the arena. The numbered square in which the front left foot of the animal under assessment rested was noted every 15 seconds. As the distance of each square from the seated operator was known, it was thus possible to calculate the following parameters: The mean distance from the human operator (defined as the average distance from the human operator on the chair over 12 readings), the time a lamb spent in a specific zone was also calculated (with zone one defined as the closest to the human and zone three the furthest from the human), and the total number of boundaries crossed between squares during the test, which was considered as an indication of the total distance travelled. Other data that were recorded to describe the behaviour of the lamb were the number of bleats and the number of times an animal urinated or defecated. These arena tests were adapted from corresponding procedures by Murphy et al. (1994) and Kilgour \& Szantar-Coddington (1995), as was previously applied at Elsenburg by Cloete et al. (2010). The arena used in this instance had different dimensions than the one used by Cloete et al. (2010). Animals were only tested once, as outcomes from the study by Murphy et al. (1994) suggested that the repeatability of measurements of temperaments were fairly high $(P>0.55)$

The normally distributed data (times spent in the respective zones, average distance from the human, number of crosses and number of bleats) were analysed by an animal model that included the single random effect of animal (Gilmour et al., 2006). Fixed effects included in the analysis were year of birth, sex and birth type. Since the size of the data base would not sustain a comprehensive genetic assessment, this study only focuses on the least square means predicted for fixed effects under an animal model, as described by Gilmour et al. (2006). The frequency of urinating and defecating events was not normally distributed. Lambs that urinated or defecated were thus expressed as proportions and compared among sex, birth type and breed groups using standard non-parametric Chi-square $\left(\chi^{2}\right)$ procedures (Van Ark, 1990).

\section{Results and Discussions}

Sex did not seem to have a marked effect for any of the behaviour traits within the three breeds (Table 1). This is in contrast to other studies, which suggested that rams are less fearful than ewes (Vandenheede \& Bouissou, 1996). The latter authors also indicated that ewes are more active, with higher 
measurements of locomotion and vocalisation. In correspondence with their report, Cloete et al. (2010) also found that ewes bleated more frequently than rams in an arena test, which was not the case in this study.

Table 1 Least square means ( \pm SE) depicting the effect of sex on behaviour traits

\begin{tabular}{lcc}
\hline \multirow{2}{*}{ Trait } & \multicolumn{1}{c}{ Sex } & Memale \\
\cline { 2 - 3 } & & $3.2 \pm 0.15$ \\
Average distance (m) & $138 \pm 7$ & $130 \pm 9$ \\
Time in Zone 1 (sec) & $32.6 \pm 6.3$ & $42.5 \pm 7.7$ \\
Time in Zone 2 (sec) & $8.9 \pm 0.89$ & $10.1 \pm 1.10$ \\
Number of crosses & $15.7 \pm 1.2$ & $12.8 \pm 1.5$ \\
Number of bleats & 0.42 & 0.37 \\
Frequency of animals urinating & \\
Frequency of animals defecating & 0.44 & 0.46
\end{tabular}

\footnotetext{
${ }^{\mathrm{a}, \mathrm{b}}$ Row means with different superscripts differ significantly $(P<0.05)$.

\# The frequency of animals that urinated or defecated during the three minute test is provided, as evaluated using a $\chi^{2}$ test.
}

There were no behavioural differences between single- or multiple-born lambs (Table 2). However, research by Hernandez et al. (2010) has shown that litter size affects the behavioural response of lambs. They reported that single-born lambs made more attempts to escape when isolated than multiples. It remains to be seen if the animals that were tested here show similar behaviour patterns when more data is gathered.

Table 2 Least square means $( \pm S E)$ depicting the effect of birth type on behaviour traits

\begin{tabular}{lcc}
\hline \multirow{2}{*}{ Trait } & \multicolumn{2}{c}{ Birth type } \\
\cline { 2 - 3 } & Single & Multiple \\
\hline Average distance (m) & $3.2 \pm 0.17$ & $3.3 \pm 0.09$ \\
Time in Zone 1 (sec) & $137 \pm 10$ & $131 \pm 5$ \\
Time in Zone 2 (sec) & $35.7 \pm 8.9$ & $39.4 \pm 4.4$ \\
Number of crosses & $10.3 \pm 1.27$ & $8.8 \pm 0.63$ \\
Number of bleats & $15.1 \pm 1.7$ & $14.4 \pm 0.9$ \\
Frequency of animals urinating & 0.40 \\
Frequency of animals defecating & 0.37 & 0.46 \\
\hline
\end{tabular}

\footnotetext{
${ }^{\mathrm{a}, \mathrm{b}}$ Row means with different superscripts differ significantly $(P<0.05)$.

\# The frequency of animals that urinated or defecated during the three minute test is provided, as evaluated using a $\chi^{2}$ test.
}

No conclusive breed differences were found for any of the traits describing the behaviour of the lambs, except for the number of bleats. Namaqua Afrikaner lambs bleated significantly $(P<0.05 ; 24.0 \pm 1.2)$ more during the three minute testing period than either Dorper (8.2 \pm 0.9$)$ or SAMM lambs (11.9 \pm 2.5$)$ (Table 3). Based on the breed difference in number of bleats, it could be argued that the Afrikaners were more anxious.

According to Hansen et al. (2001) breed differences could be as a result of selection for production and economic traits. The Namaqua Afrikaner is an unselected breed (kept only for conservation purposes), the SAMM breed is selected for meat and wool production, and the Dorper is selected for meat production. 
This difference in their development could be the reason why the Namaqua Afrikaner lambs appear to be more anxious under test conditions. In the current study there was also a tendency $(P<0.10)$ for a lower proportion of SAMM and Dorper lambs to urinate during the test. The behaviour of animals during an arena test was associated with a single nucleotide polymorphism (SNP) coding for cortisol production in Merino sheep in the study of Hough (2012). Specific traits associated with the SNP under study involved the averaged distance from the human operator as well as bleating and urinating frequency. It is not sure if similar effects will be found to operate in this genetic resource at a later stage.

Table 3 Least square means ( \pm SE) depicting the effect of breed on behaviour traits

\begin{tabular}{|c|c|c|c|}
\hline \multirow{2}{*}{ Trait } & \multicolumn{3}{|c|}{ Breed } \\
\hline & Namaqua Afrikaner & Dorper & SAMM \\
\hline Average distance (m) & $3.1 \pm 0.12$ & $3.4 \pm 0.08$ & $3.2 \pm 0.25$ \\
\hline Time in Zone 1 (sec) & $136 \pm 7$ & $127 \pm 5$ & $140 \pm 14$ \\
\hline Time in Zone 2 (sec) & $38.4 \pm 6.3$ & $41.9 \pm 4.6$ & $32.3 \pm 12.8$ \\
\hline Number of crosses & $9.4 \pm 0.9$ & $9.1 \pm 0.07$ & $10.2 \pm 1.81$ \\
\hline Number of bleats & $24.0 \pm 1.2^{\mathrm{a}}$ & $8.2 \pm 0.09^{b}$ & $11.9 \pm 2.5^{\mathrm{b}}$ \\
\hline Frequency of animals urinating & 0.30 & 0.41 & 0.50 \\
\hline Frequency of animals defecating & 0.44 & 0.50 & 0.41 \\
\hline
\end{tabular}

${ }^{\mathrm{a}, \mathrm{b}}$ Row means with different superscripts differ significantly $(P<0.05)$.

${ }^{\text {\#}}$ The frequency of animals that urinated or defecated during the three minute test is provided, as evaluated using a $\chi^{2}$ test.

\section{Conclusion}

This research has shown that there could be some differences between these three breeds that were selected for different traits and are suitable for different farming conditions in an arena test. The observed difference in the number of bleats uttered stands to reason if the development of the respective breeds is considered. Further research is necessary to see if this indication of anxiety would be related to other traits such as lamb survival and/or product quality.

\section{Acknowledgements}

We wish to thank Christie Rheeder and the personnel of the Nortier experimental farm for the maintenance and husbandry of the experimental animals. A special word of thanks is also due to Katryn Schoon and Ernst Moller for assistance with the arena test.

\section{References}

Cloete, J.J.E., Hoffman, L.C. \& Cloete, S.W.P., 2005 Behaviour of Merinos divergently selected for multiple rearing ability in response to external stimuli. Small Rumin. Res. 60, 227-236.

Cloete, J.J.E., Cloete, S.W.P. \& Hoffman, L.C., 2010. Behaviour of Merinos selected for multiple rearing ability in response to human beings. Proc. $9^{\text {th }}$ World Cong. Gen. Appl. Livest. Prod., 1-6 August 2010, ISBN 978-3-00-031608-1. http://www.kongressband.de/wcgalp2010/assets/pdf/0703.pdf. (Leipzig, Germany).

Cloete, S.W.P. \& De Villiers, T.T., 1987. Production parameters for a commercial Dorper flock on extensive pasture. S. Afr. J. Anim.Sci. 27, 121-127.

Cloete, S.W.P. \& Olivier, J.J., 2010. South African Sheep and Wool Industry. In: The International Sheep and Wool Handbook. Ed: Cottle, D.J., Nottingham University Press, Nottingham. England. pp. 95-112.

Dodd, C.L., Pitchford, W.S., Hocking Edwards, J.E. \& Hazel, S.J., 2012. Measures of behavioural reactivity and their relationship with production traits in sheep: A Review. Appl. Anim. Behav. Sci. 140, 1-15. 
Gilmour, A.R. \& Gogel, B.J., 2006. ASREML- User Guide Release 2.0 VSN International Ltd, Hemel Hempstead, HP11ES, UK.

Hansen, I., Christiansen, F., Hansen, H.S., Braastad, B. \& Bakken, M., 2001. Variation in behaviour responses of ewes towards predator-related stimuli. Appl. Anim. Behav. 70, 227-237.

Hernandez, C.E., Matthews, L.R., Olivier, M.H., Bloomfield, F.H. \& Harding, J.E., 2010. Effects of sex, litter size and periconceptional ewe nutrition on offspring behaviour and physiological response to isolation. Physiol. Behav. 101, 588-594.

Hough, D., 2012. Comparison of two CYP17 isoforms: Implications for cortisol production in the South African Merino. PhD thesis, Department of Biochemistry, University of Stellenbosch, Stellenbosch, South Africa.

Kilgour, R.J. \& Szantar-Coddington, M.R., 1995. Arena behaviour of ewes selected for superior mothering ability differs from that of unselected ewes. Anim. Rep. Sci. 37, 133-141.

Lawrie, R.A., 1998. Lawrie’s Meat Science, sixth ed. Woodhead Publ. Ltd., Cambridge, England.

Murphy, P.M., Purvis, I.W., Lindsay, D.R., Le Neindre, P., Orgeur, P. \& Poindron, P., 1994. Measures of temperament are highly repeatable in Merino sheep and some are related to maternal behaviour. Proc. Aust. Soc. Anim. Prod. 20, 247-250.

Van Ark, H., 1990. Freq.exe - For the comparison of frequencies. Datametrical Services, Department of Agriculture, Private Bag X116, Pretoria 0001, South Africa.

Vandenheede, M. \& Bouissou, M.F., 1996. Effects of castration on fear reaction of male sheep. Appl. Anim. Behav. Sci. 34, 211-224. 